Nuclear Explosion Monitoring Research and Engineering (NEMRE\&E) Program

Final Technical Report

Award Number DE-FC52-03NA99513

\title{
Explosion Source Phenomena Using Soviet, Test-era, Waveform Data
}

\author{
Principal Investigator: Paul G. Richards \\ Institution: Lamont-Doherty Earth Observatory of Columbia University
}

\section{Teaming Members:}

Vitaly I. Khalturin, Tatyana G. Rautian, and Paul G. Richards, all at Columbia University

W. Scott Phillips

at Los Alamos National Laboratory

\section{Distribution Unlimited}




\section{Executive Summary}

We have taken advantage of numerous analog seismograms of Soviet nuclear explosions that occurred from 1961 to 1988 , and that were recorded at distances around 700 to $1000 \mathrm{~km}$ from the USSR's Semipalatinsk nuclear test site in Kazakhstan, and China's nuclear test site at Lop Nor, to augment the limited modern recordings of such explosions. These Soviet-era seismograms consist of paper records, of a special type using narrow band filters that enables measurements to be made of the spectra of ground motion.

The measurements from analog recordings made by Rautian and Khalturin at Columbia University were delivered on a CD and have been integrated into a large scale study at Los Alamos National Laboratory that was based upon modern digital data. The measurements made from the analog data have been used to give source spectral estimates of 126 Semipalatinsk underground nuclear explosions. These estimates have been used to calibrate amplitude-yield relationships, along with results from digital records of underground explosions in Asia.

The project was needed because there has been significant growth in the number of digital seismographic stations in Asia since about 1994, but during this period there have been very few underground nuclear explosions to record. By going back to the analog recordings made during the Soviet era, it has been possible to get a good idea of the spectral nature of the signals that the modern stations must be capable of recording, and a good idea also of how to interpret the records that the modern stations may eventually make if nuclear explosions occur in this region in future. 


\section{Comparison of actual accomplishments with the original goals and objectives}

The original goals and objectives were to use analog seismic recordings made on territory of the Soviet Union during the era of routine nuclear testing, to augment the database of digital regional signals of underground nuclear explosions, and to evaluate the spectral scaling of explosion signals of different yields. This work was accomplished as planned.

\section{Summary of project activities}

During the nuclear testing era, the former Soviet Union carried out extensive observations of underground nuclear explosions, recording both their own shots and those of foreign nuclear states. Between 1961 and 1989, the Soviet Complex Seismological Expedition deployed seismometers at time-varying subsets of over 150 sites to record explosions at regional distances from the Semipalatinsk and Lop Nor test sites and from the shot points of peaceful nuclear explosions. This data set included recordings from broadband, multi-channel $\mathrm{ChISS}^{1}$ seismometers that produced a series of narrow band outputs, which could then be measured to perform spectral studies. Quantitative, pre-digital era investigations of high-frequency source scaling relied on this type of data (e.g., Aki and Chouet, 1975; Rautian and Khalturin, 1978; Tsujiura, 1978). To augment data sets of central Central Asia explosions, we have measured and compiled 537 ChISS coda envelopes for 124 events recorded at Talgar, Kazakhstan, at a distance of about $750 \mathrm{~km}$ from Semipalatinsk. Envelopes and calibration levels were measured manually from photo paper records for seven bands between 0.08 and $5 \mathrm{~Hz}$. We obtained from 2 to 10 coda envelope measurements per event, depending on the event size and instrument magnification. Coda lengths varied from 250 to $1400 \mathrm{~s}$. For small events, only bands between 0.6 and $2.5 \mathrm{~Hz}$ could be measured. Envelope levels were interpolated or extrapolated to $500 \mathrm{~s}$ and we have obtained the dependence of this quantity on magnitude. Coda $\mathrm{Q}$ was estimated and found to increase from 232 at $0.08 \mathrm{~Hz}$ to 1270 at $5 \mathrm{~Hz}$. These relationships were used to construct an average scaling law of coda spectra for Semipalatinsk explosions. Significant differences from average scaling are observed and may result from variations in emplacement conditions. The ChISS envelope data have been integrated into coda processing at Los Alamos National Laboratory (LANL) by applying ChISS filter bands to modern, digital data from central Central Asia, for purposes of magnitude and yield calibration.

In addition, we have compiled regional, direct phase measurements for ChISS recordings at Talgar, Garm, Zerenda, and Novosibirsk. The ChISS envelope data have been integrated into coda processing at Los Alamos National Laboratory (LANL) by applying ChISS filter bands to modern, digital data from central and east Asia, for purposes of yield calibration. The difference in manual versus digital measurement methods are captured in site terms that are higher by up to $0.5 \log _{10}$ units for ChISS data, relative to modern Talgar data due to the measurement of peak, rather than mean envelopes. After correction for site and path effects, ChISS amplitudes compare

\footnotetext{
${ }^{1}$ ChISS is the Russian abbreviation for multichannel spectral seismometer. In this instrument the signal from the seismometer is passed through a system of narrow bandpass filters and recorded on photo paper. ChISS instruments have from 8 to 16 channels in the frequency range from $100 \mathrm{sec}$ to $40 \mathrm{~Hz}$. We used data mostly from 7 channels, ranging from 0.08 to $5 \mathrm{~Hz}$.
} 
well to measurements from the Borovoye archive for events in common. Direct wave measurements have been used to construct spectra for Semipalatinsk explosions, and can be used to explore the behavior of regional phase amplitudes with shot point and emplacement condition.

\section{RESEARCH ACCOMPLISHED}

\section{The ChISS Instrument}

The ChISS instrument is a real-time, spectral-analyzing seismic recording system, created by K.K. Zapolsky in the early 1950s. It produced band-passed traces in several (usually 7-10) frequency channels over a broad band from $100 \mathrm{sec}$ to $40 \mathrm{~Hz}$. The components of a ChISS system are the seismometer, calibration device, amplifier, filter bank, and galvanometers with a photo-paper recording device. Instrument calibration was achieved by each seismometer having an excitation coil with a separate magnet to input the calibration signal. The frequency of the calibration electric signal was slowly decreased in time from the high end of the highest frequency filter to the low end of the lowest frequency filter. The shape of the response to this signal on the seismogram exactly corresponds to the frequency response of the seismometer-filter-galvanometer system. The impulse response consists of 1.5-2 periods (3-4 extrema). Such a short period of transition guarantees minimal distortion of the initial seismic signal and stabilizes the envelope shape. Filters used in ChISS systems are characterized by the low and high band limits (at 0.7 maximum magnification), $\mathrm{f} 1$ and $\mathrm{f} 2$; the central frequency, $\mathrm{fc}$; the absolute bandwidth, $\mathrm{df}=\mathrm{f} 2 \mathrm{-} \mathrm{f} 1$; and the relative bandwidth, (f2 - f1)/fc.

The ChISS filter parameters at the Talgar station used in this study are shown in Tables 1 and 2. Parameters were changed in September 1971 when the system was improved to include two sets of filters for independent shortperiod (ShP) and long-period (LP) seismometers, as well as independent systems of calibration and recording. The LP and ShP ChISS instruments employ Soviet SKD and SKM seismometers, respectively. Two identical ChISS filters, with central frequency $0.62 \mathrm{~Hz}$, are output from both systems. The calibration signal was recorded daily on each short period ChISS seismogram and once a week on long period ChISS seismograms.

Table 1. Early ChISS parameters (Sep 1961 - Aug 1971)

\begin{tabular}{|l|l|l|l|l|l|}
\hline f1 - f2 (Hz) & $0.27-0.4$ & $0.54-0.84$ & $1.1-1.7$ & $2.3-3.6$ & $4.6-7.1$ \\
\hline fc (Hz) & 0.32 & 0.67 & 1.36 & 2.9 & 5.7 \\
\hline Width & 0.40 & 0.45 & 0.45 & 0.45 & 0.45 \\
\hline
\end{tabular}

Table 2. Standard ChISS parameters (Sep 1971 - Oct 1990)

\begin{tabular}{|l|l|l|l|l|l|l|l|l|}
\hline LP or ShP & LP & LP & LP & LP & ShP & ShP & ShP & ShP \\
\hline f1 - f2 $(\mathrm{Hz})$ & $0.05-0.1$ & $0.1-0.2$ & $0.2-0.4$ & $0.5-0.8$ & $0.5-0.8$ & $1.0-1.6$ & $2.0-3.2$ & $4-6.4$ \\
\hline fc $(\mathrm{Hz})$ & 0.08 & 0.14 & 0.28 & 0.62 & 0.62 & 1.25 & 2.5 & 5.0 \\
\hline Width & 0.7 & 0.7 & 0.7 & 0.5 & 0.5 & 0.5 & 0.5 & 0.5 \\
\hline
\end{tabular}

\section{Talgar Explosion Data}

The Talgar ChISS station began operating in September 1961. It recorded almost all Soviet underground nuclear tests (UNTs) from the Semipalatinsk test site (STS), including the first two STS UNTs on Oct 11, 1961 and Feb 2, 1962 until the final test of Oct 19, 1989. Many small magnitude UNTs, which were not recognized by western stations, have been recorded by ChISS station TLG (Khalturin et al., 2001).

For this study, we manually measured coda envelopes of 178 Talgar ChISS records of 124 UNTs and entered the data into the computer. More than 500 coda envelopes were analyzed from channels between $0.08 \mathrm{~Hz}$ and $5 \mathrm{~Hz}$.

For measurable channels, the number of coda amplitudes we obtained varied from 3-5 to 10-12, depending on the signal strength and the magnification of the instrumentation. For small events only two or three channels had records with coda large enough to be measured, generally $0.62,1.25$ and $2.5 \mathrm{~Hz}$. For large events 5,6 and up to 8 channels 
were measurable. Elapsed time relative to the event origin varied from $250 \mathrm{sec}$ up to as much as $1400 \mathrm{sec}$ in some cases.

\section{Observed Direct and Coda Phases}

We consider the coda as consisting of two parts. The first portion is the tail of the dominant direct wave, originating from scattering in the vicinity of the ray path. The second portion is the "late coda" or just "coda," originating from scattering throughout a large volume of the Earth, of dimension greater than the epicentral distance. Excitation of the late coda is insensitive to path variations, but depends on variations in spectral content radiated by each individual event. For this reason, we rely on the late coda to study spectral scaling and explosion emplacement conditions.

We must define the time at which the late coda begins, which entails detailed investigation of the dominant direct waves preceding the coda. We observe three intensive waves along the STS-Talgar path: 1) the $\boldsymbol{L} \boldsymbol{g}$ wave train, arriving at Talgar at 210-215 sec, reaching maximum intensity at about 220-240 sec and remaining intense until 250-270 sec; 2) the $\boldsymbol{R g}$, arriving at $240 \mathrm{sec}$, with maximum at 260-270 sec and intense until $300 \mathrm{sec}$; and 3) the $\boldsymbol{L o}$, which is a wave group observed in the 340-450 sec time interval, perhaps a short-period surface wave train with group velocity $1.9-2.2 \mathrm{~km} / \mathrm{sec}$, observed on the $0.28-1.25 \mathrm{~Hz}$ channels with amplitude just above the coda. The $\boldsymbol{L o}$ group is weaker than $\boldsymbol{R} \boldsymbol{g}$ on long-period channels, and weaker than $\boldsymbol{L} \boldsymbol{g}$ on short-period channels. At mid-period channels, 0.28 and $0.32 \mathrm{~Hz}, \boldsymbol{L g}, \boldsymbol{R g}$ and $\boldsymbol{L o}$ have roughly equal amplitudes. Each of these waves produces its own coda, which overlaps with coda of the other phases.

Aki's "rule of thumb" for coda measurement defines the beginning of the late coda as twice the travel time of the associated direct wave. In reality the factor of two can vary. We find the critical time empirically for our study. This is done based on observations of the envelope shapes, including both early and late coda. We measure the envelope beginning soon after the passage of $\boldsymbol{L} \boldsymbol{g}$ or $\boldsymbol{R} \boldsymbol{g}$ waves.

To manually obtain the coda envelope from a photo paper record, one must choose each individual moment of time to measure. We choose measurement times such that monotonically decreasing amplitudes are obtained. Strict adherence to this rule enhances repeatability, which we have verified by comparing measurements obtained independently by two analysts. Further testing has shown that measurements from the short and long period recording in the common band, $0.62 \mathrm{~Hz}$, are the same.

The accuracy of manual measurements of ChISS envelopes depends on amplitude. The accuracy is lower for small amplitudes (below 1-2 $\mathrm{mm}$ ) and large amplitudes (over 70-100 $\mathrm{mm}$ ). We estimate that amplitudes less than $1 \mathrm{~mm}$ can be measured with error on the order of the amplitude itself. Therefore we eliminate all data below this level. The difficulty with large amplitudes is that waveforms from neighboring channels can overlap. Channels are recorded side by side and are separated by $70 \mathrm{~mm}$; thus, peak-peak amplitudes larger than 70-100 mm overlap. From our experience, measurement quality depends on brightness of the record.

Occasionally, errors result from mistakes in measuring calibration levels. In such cases, both coda and direct wave amplitudes have the same discrepancy for that channel. This cannot be seen in individual envelopes, but is revealed in the spectra of individual events and in correlations between amplitude and magnitude. Such comparisons have been made to control the quality of the Talgar data set.

We summarize observations of the coda envelopes by band in the following. All the individual envelopes were normalized to the level 1 at lapse time $500 \mathrm{sec}$. The bands of frequency $=0.62 \mathrm{~Hz}$ from the LP and ShP ChISS systems were combined. The envelopes (Figures 1 abcdef) are corrected for geometrical spreading, assumed to be $\mathrm{t}^{-0.5}$ for 0.08 and $0.14 \mathrm{~Hz}$ channels and $\sim \mathrm{t}^{-1}$ for channels 0.28 and higher.

0.08 and 0.14 Hz: Envelopes from the two long period channels are similar, showing a dramatic decrease between 250 and 300-320 sec (the $\boldsymbol{R g}$ wave tail, Figure 1a). We observe a small increase between 350 and $450 \mathrm{sec}$. This is a long-period $\boldsymbol{L o}$ wave. The $\boldsymbol{R} \boldsymbol{g}$ tail for the $0.14 \mathrm{~Hz}$ channel is weaker than that observed on the $0.08 \mathrm{~Hz}$ channel. The increase at $400-450 \mathrm{sec}$ is nearly invisible. The $\boldsymbol{L o}$ wave is visible itself, but its coda is not, because of strong attenuation in the upper crust. The uniformly decaying envelope begins at lapse times of 500-550 sec.

0.28 and $0.32 \mathrm{~Hz}$ : Envelopes from these bands differ from those of the long period channels (Figure $1 \mathrm{~b}$ ). $\boldsymbol{R g}$ is very weak at these frequencies and no tails are observed. All the wave groups, $\mathbf{L g}, \boldsymbol{R g}$ and $\boldsymbol{L o}$ are of similar amplitude and little exceed the irregular oscillations before and after them. A very smooth maximum is observed between 270 
and $350 \mathrm{sec}$, corresponding to a velocity interval from 2.1 to $2.8 \mathrm{~km} / \mathrm{sec}$, likely the result of a short-period surface wave $\boldsymbol{L o}$, propagating in the upper crust. This wave is usually seen clearly at distances of 200 to $250 \mathrm{~km}$. But because of strong scattering in the upper crust the $\boldsymbol{L} \boldsymbol{o}$ waves produce intense coda, then decrease and almost disappear at $750 \mathrm{~km}$. At this distance, the $\boldsymbol{L} \boldsymbol{o}$ wave train does not dominate its own coda. This happens because of strong loss of $\boldsymbol{L} \boldsymbol{o}$ energy by both scattering and attenuation processes. This produces a relatively intense coda that attenuates faster than $\boldsymbol{L} \boldsymbol{g}$ coda. That is because $\boldsymbol{L} \boldsymbol{g}$ travels throughout the entire crust, including the less attenuating lower crust. We conclude that the $\boldsymbol{L o}$ coda dominates at lapse-time 400-550 sec. But then it decreases and after 500$550 \mathrm{sec}$ the $\boldsymbol{L} \boldsymbol{g}$ coda begins to dominate. This conclusion is based on the coda slopes, which differ between 350-500 and 500-1000 sec time ranges. Therefore, we considered two separate codas based on these time limits in this study.

0.62 and 0.67 Hz: At this frequency $\boldsymbol{L g}$ is much more intense than $\boldsymbol{L o}$ and the coda is associated with the $\boldsymbol{L g}$ (Figure 1c). But between 350 and $430 \mathrm{sec}$ envelopes flatten, indicating an additional source of scattered waves. This flat portion is, likely, a peak of the $\boldsymbol{L} \boldsymbol{o}$ wave, nearly hidden within its own coda. The corresponding arrival time gives a velocity of $1.8-2.1 \mathrm{~km} / \mathrm{sec}$. The envelope decay rate between 450 and $1200 \mathrm{sec}$ corresponds to a coda $\mathrm{Q}$ of 525 , which is too high for upper crust propagation. We conclude that at $0.62 \mathrm{~Hz}$ the observed coda originated mostly from $\boldsymbol{L} \boldsymbol{g}$; only the peak shows above the coda. The coda created from $\boldsymbol{L} \boldsymbol{o}$ is mixed with the $\boldsymbol{L} \boldsymbol{g}$ coda at times between 350 and $450 \mathrm{sec}$.

1.25 and $1.36 \mathrm{~Hz}$ : The features we observe in these bands are the similar to those of the $0.62 \mathrm{~Hz}$ channel (Figure $1 \mathrm{~d})$.

2.5 and 2.9 Hz: These envelopes show a uniform linear decrease from nearly the beginning ( $300 \mathrm{sec}$, Figure 1e). The initial part of the envelope, 250 to $300 \mathrm{sec}$, consists of a direct $\boldsymbol{L} \boldsymbol{g}$ tail. No sign of $\boldsymbol{L} \boldsymbol{o}$ exists. We conclude that $2.5 \mathrm{~Hz}$ coda originated from high-frequency $\boldsymbol{L} \boldsymbol{g}$. Decay slopes differ slightly between 2.5 and $2.9 \mathrm{~Hz}$ envelopes.

5 and 5.7 Hz: This high-frequency coda is short and straight, only a few measurements exist beyond 500 sec, none are recorded at times greater than $550 \mathrm{sec}$ (Figure 1f).

We summarize our observations as follows: 1) the dominant wave is $\boldsymbol{R g}$ at 0.08 and $0.14 \mathrm{~Hz}, \boldsymbol{L g}$ dominates at 0.62 $2.5 \mathrm{~Hz}$ and displays a short tail, $\boldsymbol{L o}$ dominates at $0.28 \mathrm{~Hz}$ and $\boldsymbol{L} \boldsymbol{g}$ is nearly invisible and no tail exists at $5 \mathrm{~Hz}$; and 2) the short-period surface wave, $\boldsymbol{L o}$, exists on almost all channels from 0.08 to $2.5 \mathrm{~Hz}$, and is seen as a wide weak maximum, exceeding the straight coda envelope by a factor of only 1.2 to 1.7 , and we define the beginning of late coda at $500-550$ for $0.08 \mathrm{~Hz}, 450-500 \mathrm{sec}$ for $0.14-0.28 \mathrm{~Hz}, 400-450 \mathrm{sec}$ for $1.25 \mathrm{~Hz}$ and $300 \mathrm{sec}$ for $2.5 \mathrm{and} 5 \mathrm{~Hz}$.

We chose the logarithm of the coda envelope at lapse time $500 \mathrm{sec}$ as a standard measure of coda intensity. These are the values used to construct coda spectra.

\section{Coda Attenuation}

We estimate coda Q based on the standard equation (Aki and Chouet, 1975) and results are shown in Table 3. Coda Q was measured separately for earlier and later lapse time intervals for the $0.28 \mathrm{~Hz}$ band, as defined above.

We believe that these two intervals represent $\boldsymbol{L} \boldsymbol{o}$ and $\boldsymbol{L} \boldsymbol{g}$ coda, scattered in the upper crust (Lo coda) and in the whole crust, or, alternatively, in the crust and lithosphere ( $\boldsymbol{L} \boldsymbol{g}$ coda).

\section{Raw Coda Spectra}

The coda spectra means the logarithm of the value of coda envelope at lapse time $500 \mathrm{sec}$, measured in $\mathrm{nm} / \mathrm{sec}$. The spectra were found in a wide frequency band, from 0.08 or $0.14 \mathrm{~Hz}$ up to $5.0 \mathrm{~Hz}$, only for large events. For small events the coda exists on only three channels: $0.62-2.5 \mathrm{~Hz}$.

The coda raw spectra of Balapan and Degelen tests are shown in Figures 2a and 2b. The events have a spectral peak with position varying between 0.62 and $1.25 \mathrm{~Hz}$.

In general the Degelen and Balapan spectra are similar, but there are some systematic differences between these two groups. Degelen spectra are a little bit wider than those of Balapan, and have more high frequency energy. These differences are not a result of wave propagation (the volume of scattering media is the same), but are caused by various conditions at the source, and rock properties in these two areas of STS. The smallest events (down to $\mathrm{m}=$ 
4.5), with three points of spectrum only, show variable peak positions, either about $1 \mathrm{~Hz}$ or less than $0.6 \mathrm{~Hz}$. This indicates a variation in source scaling that might originate with differences in emplacement conditions and that will cause scatter in the observed relationships between high frequency coda amplitude and event magnitude (see below). Generalizing all the spectra into a common scaling law allows us to use deviations of individual spectra from the standard spectra as an indication of source condition.

\section{Table 3. Values of coda $Q$.}

\begin{tabular}{|l|l|l|}
\hline $\begin{array}{l}\text { Channel, } \\
f(\mathrm{~Hz})\end{array}$ & Qc & $\begin{array}{l}\text { in t (sec) } \\
\text { interval }\end{array}$ \\
\hline 0.08 & 232 & $550-1400$ \\
\hline 0.14 & 252 & $500-1200$ \\
\hline 0.28 & 200 & $300-500$ \\
\hline 0.28 & 323 & $500-1400$ \\
\hline 0.32 & 180 & $350-500$ \\
\hline 0.32 & 346 & $500-1000$ \\
\hline 0.62 & 520 & $450-1100$ \\
\hline 0.67 & 525 & $400-1000$ \\
\hline 1.25 & 685 & $400-950$ \\
\hline 1.36 & 625 & $350-900$ \\
\hline 2.5 & 920 & $300-750$ \\
\hline 2.9 & 980 & $300-600$ \\
\hline 5 & 1270 & $300-500$ \\
\hline 5.7 & 1400 & $270-400$ \\
\hline
\end{tabular}

\section{Coda Amplitude vs. Magnitude}

We obtained relationships between coda amplitudes and magnitude for each frequency channel. Figure 3abcd shows examples of such relationships $(0.28,0.62,1.25$ and $2.5 \mathrm{~Hz})$. The magnitudes were taken mostly from $\mathrm{AWRE}^{2}$ estimates. If AWRE data were not available, we used the mb we obtained from energy class values estimated from records of local seismic stations (as described by Khalturin et al. 2001). For each frequency the slope is higher for small events and became lower for large ones. The slope of the relationship decreased with event size, reflecting saturation of the 1-Hz magnitude scale for larger events. At high frequencies $(>1 \mathrm{~Hz})$ the high slope of small events is about 1.33 and the low slope for large events is about 1.0. At low frequencies $(\mathrm{f}<1 \mathrm{~Hz})$ the high slope is about 1.0 and the low slope is about 0.65. The change of slope takes place at magnitude about 5.6-5.8 (Figure 4).

These relationships can be used to create a scaling law for STS explosions.

\section{Scaling Law of Coda Spectra}

To create a scaling law we first estimate the spectrum for a fixed magnitude and then use the set of slopes, dependent on frequency and magnitude, to extrapolate the spectra for several magnitude values. We chose to use $\mathrm{m}$ $=5.8 \pm 0.25$ to obtain the basic spectrum. Events of this size are numerous and their spectra cover our entire frequency range $(0.08-5.0 \mathrm{~Hz})$. It is at this magnitude that the slope of coda amplitude vs. magnitude changes. The scaling law obtained was created for all bins of magnitude and frequency for which observed data are available (Figure 5). Note, again, the scaling law obtained is just a smoothed picture. We believe the most important observations are the individual deviations of real spectra from this averaged one and these remain a focus of our work. We build a common scaling of coda spectra for both Degelen and Balapan events. The individual deviation from this scaling law will be an indication of source conditions of the underground nuclear test.

\section{Additional Data}

${ }^{2}$ AWRE $=$ Atomic Weapons Research Establishment, which includes the British group also known as Blacknest. 
Four civilian ChISS recording sites were established by the Soviet Union in the region surrounding the Semipalatinsk test site (Figure 6). Examples of long-period system seismograms from the ChISS station at Zerenda (ZRN) are given in Figure 7.

In addition to the Talgar measurements reported above, we measured ChISS peak amplitudes for regional phases from 226 UNTs at the four ChISS stations, on multiple band channels, including two gain levels for certain records, and entered into electronic form. The measured phases were Pn, P2 (secondary Pn arrival), Pg, Sn, Li, Lg1, Lg2, $\operatorname{Lg} 3$ (various Lg peaks) and $\mathrm{Rg}$, and we recovered 1753, 1439, 1469, 1430, 91, 1305, 1368, 1265, and 542 measurements for each phase, respectively, totaling 10,662 measurements overall. We also obtained measurements for a small number of chemical explosions and for the March 20,1976, Semipalatinsk earthquake.

\section{Integration into Coda Processing}

Talgar ChISS coda have been integrated into coda processing at LANL by applying ChISS filter bands (Tables 1 and 2) to digital data from central and east Asia, including digital seismograms from the Borovoye archive, STsRTSG recording system (Kim and Ekström, 1996). Talgar envelopes were used in their raw form, under the assumption that differences in measuring envelopes manually and automatically would be consistent and would then be absorbed in frequency dependent site terms. To evaluate the Talgar ChISS coda results, we compared pathcorrected coda amplitudes with common events recorded at Borovoye (Figure 8). Results show offsets that we attribute to measurement method (Figure 9), and show scatter that is very tight (standard deviation of differences less than 0.2 , and often less than 0.1 ). These levels compare favorably with those observed between modern digital stations (standard deviation 0.1 or less). The Talgar ChISS results can be used in yield calibration studies.

\section{Phase Amplitude Data}

We have completed, and quality controlled, a large set of amplitudes for regional phases for Semipalatinsk explosions recorded at four ChISS stations. Sample spectra for a variety of phases are shown in Figure 10 for a number of events that include the first and second Soviet underground tests, October 11, 1961, and February 2, 1962, respectively. We also show comparisons between spectra of events from the same adits (Figure 11). These comparisons can help to understand effects of near source damage on regional signals (these show very little effect) and, in the absence of such effects, can give bounds on repeatability, after possible source scaling effects are accounted for. Discriminant ratios can also be studied using these data and an example of the behavior of cross-phase discriminants with frequency is shown in Figure 12. Finally, variation of discriminants with shot location and emplacement conditions can be studied. We show the variation of $\mathrm{P} 2 / \mathrm{Pn}$ ratios, a measure of $\mathrm{P}$ complexity, in Figure 13, demonstrating marked differences between the Balapan and Degelen source regions, as well as coherent variations across the Degelen area. We suspect these variations are due to wave propagation effects.

\section{CONCLUDING SUMMARY}

We manually measured coda envelopes from Talgar ChISS analog records for 124 STS explosions that occurred between 1961 and 1988. These data were used to study the composition of the coda for the STS-Talgar path, to define coda limits, to estimate coda attenuation, and to construct a scaling law of explosion spectra. The coda data have been integrated into LANL coda calibration procedures. The ChISS data have been tested for consistency with existing Borovoye digital data from events recorded in common, and are suitable for use in yield calibration work. Phase amplitude measurements for Semipalatinsk explosions recorded at four ChISS stations have also been collected, entered, and quality controlled. Examples of spectra are given, including spectra for events in the same adits. These data will be useful for studying variations in discriminant ratios that might result from shot point location or emplacement conditions. 


\section{REFERENCES}

Aki, K. and B. Chouet (1975). Origin of coda waves: attenuation, and scattering effects. J.Geophys.Res., 80, 33223342.

Khalturin V.I., T.G. Rautian, P.G. Richards (2001). A study of small magnitude seismic events during 1961-1989 on and near the Semipalatinsk Test Site, Kazakhstan, Pure and Appl. Geoph., 158, 143-172.

Kim, W. Y., and G. Ekström, (1996). Instrument responses of digital seismographs at Borovoye, Kazakhstan, by inversion of transient calibration pulses, Bull. Seism. Soc. Am., 86: 191-203.

Rautian, T.G and V.I. Khalturin (1978). The use of the coda for determination of the earthquake source spectrum. Bull. Seism. Soc. Am., 68, 923-948.

Rautian, T. G., V. I. Khalturn, W.S. Phillips and P.G. Richards, (2004). Explosion source phenomena using Soviet test era waveform data, in Proceedings of the 26th Seismic Research Review: Trends in Nuclear Explosion Monitoring, LA-UR-04-5801, Vol. 1, 457-466, September 21-23, Orlando, FL.

Tsujiura, M. (1978). Spectral analysis of the coda waves from local earthquakes. Bull. Earthquake Res. Inst., 53, 148. 


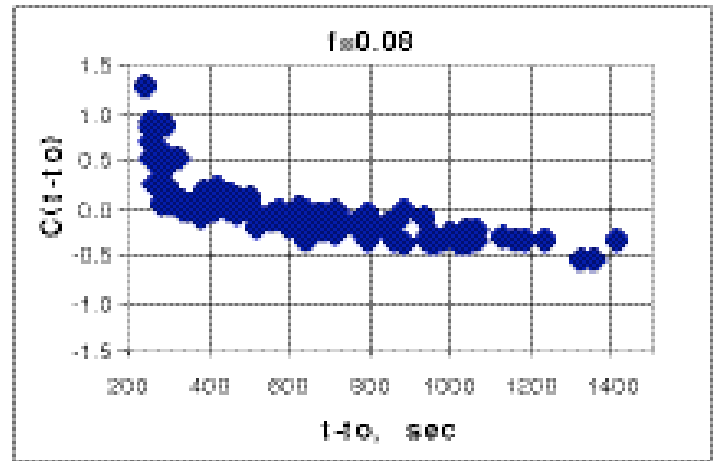

a
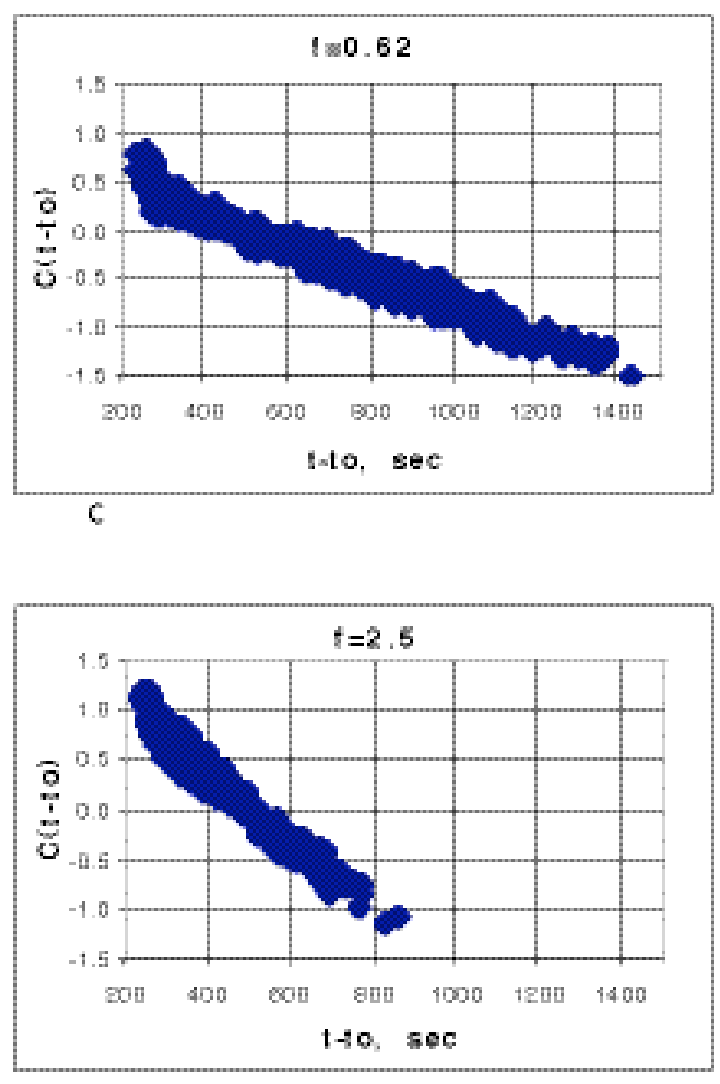

e

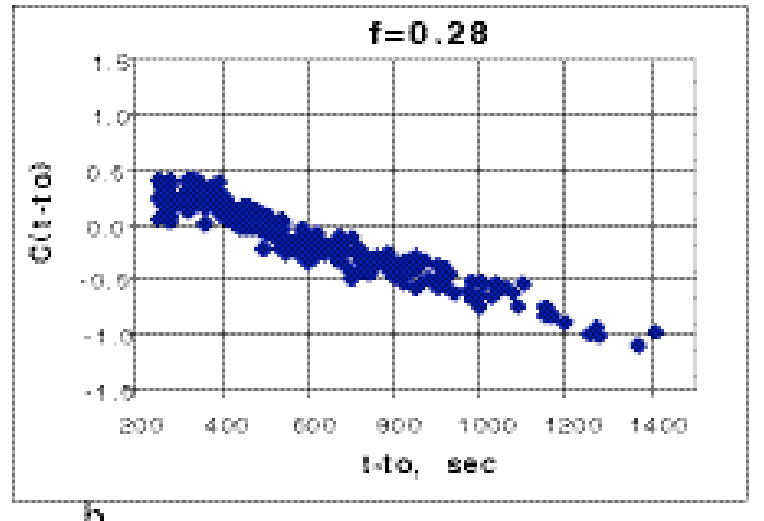

b
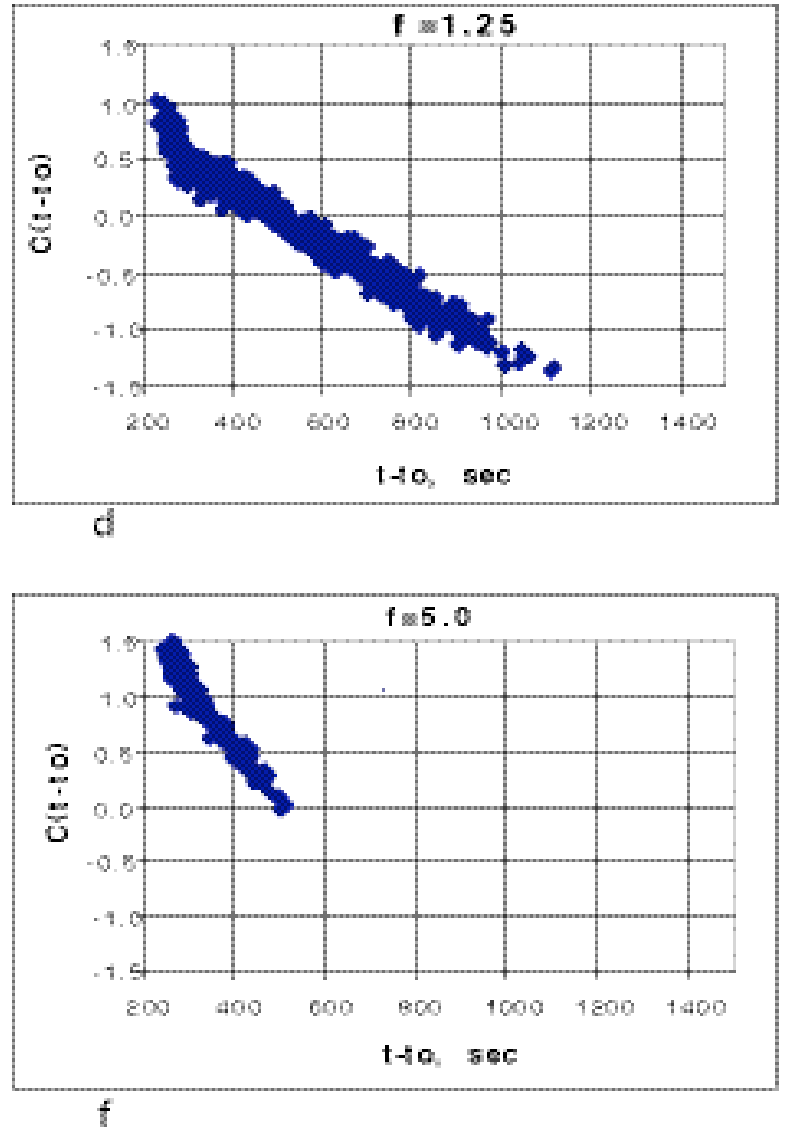

Figure 1. Normalized coda envelopes six channels. (a) is for the $0.08 \mathrm{~Hz}$ channel, (b) is for the $0.28 \mathrm{~Hz}$ channel, (c) is for the $0.62 \mathrm{~Hz}$ channel, (d) is for the $1.25 \mathrm{~Hz}$ channel, (e) is for the $2.5 \mathrm{~Hz}$ channel, and (f) is for the $5 \mathrm{~Hz}$ channel. 

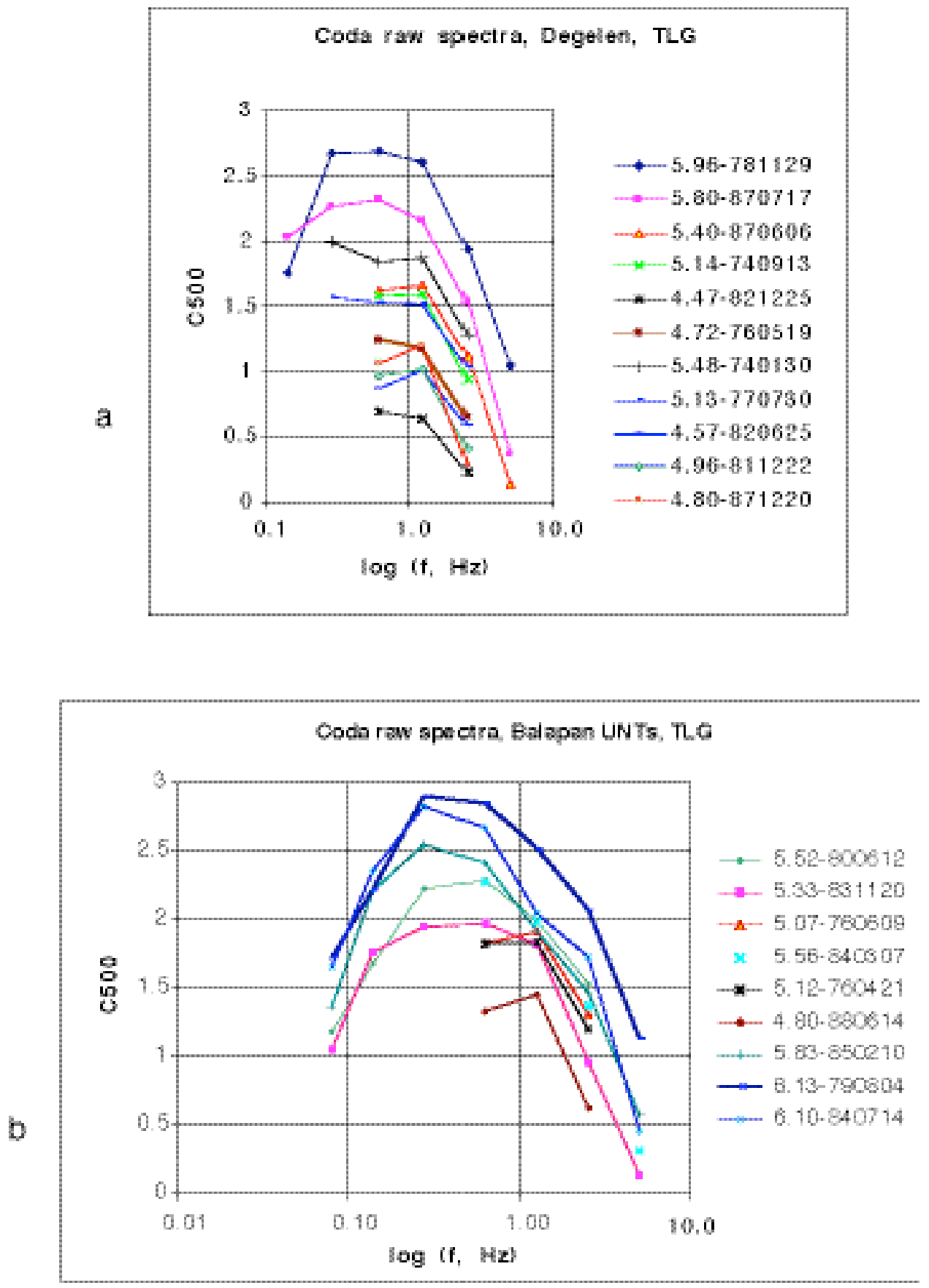

Figure 2. Raw coda spectra, (a) for Degelen explosions, and (b) for Balapan explosions. 


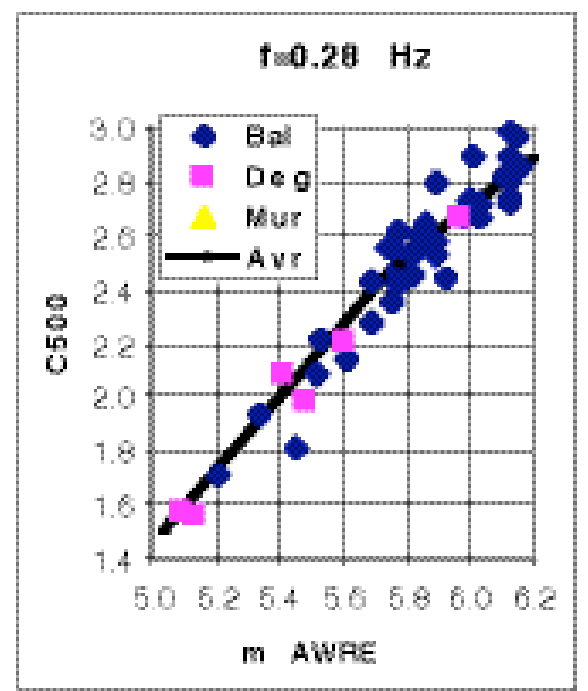

a

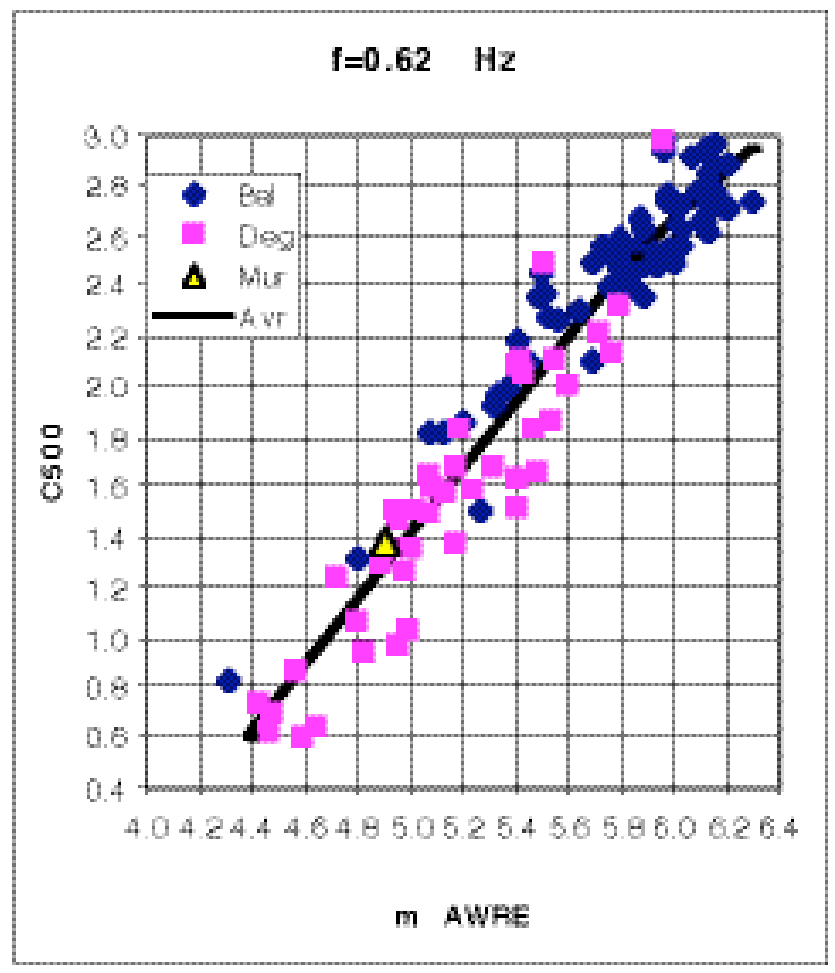

b

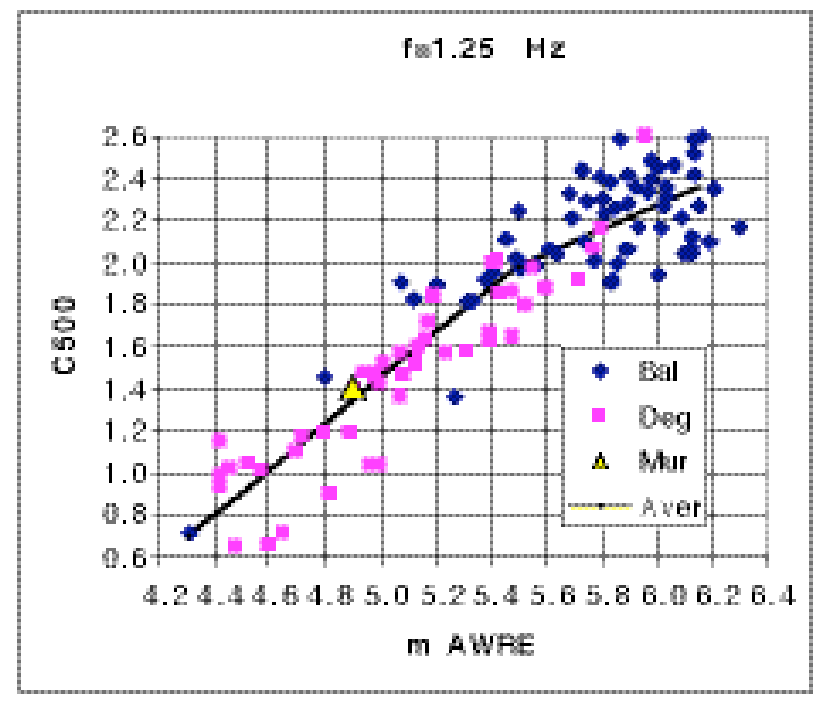

c

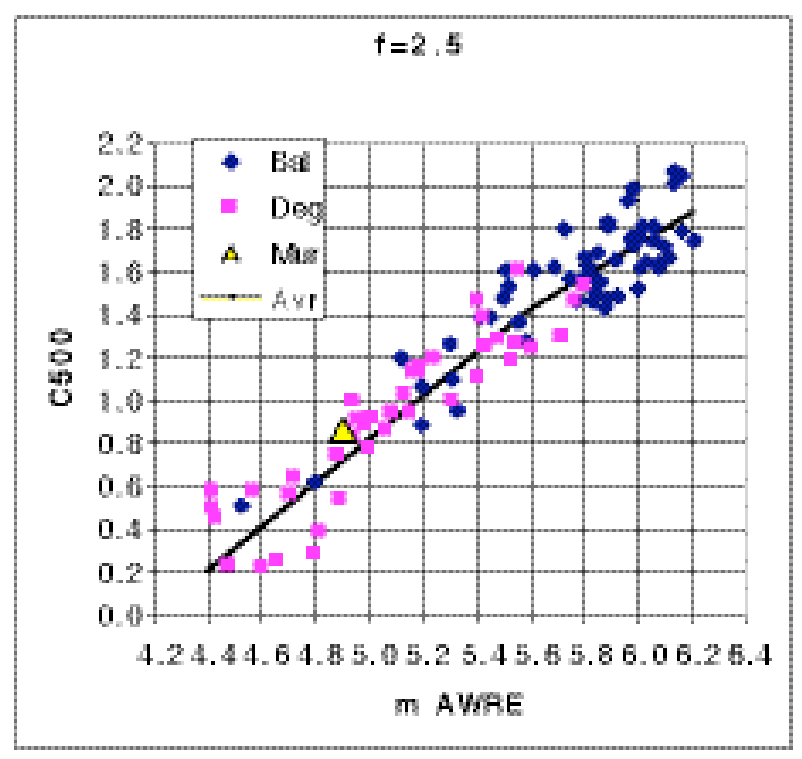

d

Figure 3. Coda - magnitude relations,

(a) for $f=0.28 \mathrm{~Hz}$, (b) for $f=0.62 \mathrm{~Hz}$, (c) for $f=1.25 \mathrm{~Hz}$, and (d) for $f=2.5 \mathrm{~Hz}$. 
Slope of C500 vs $\mathrm{m}$ for large and small UNTs

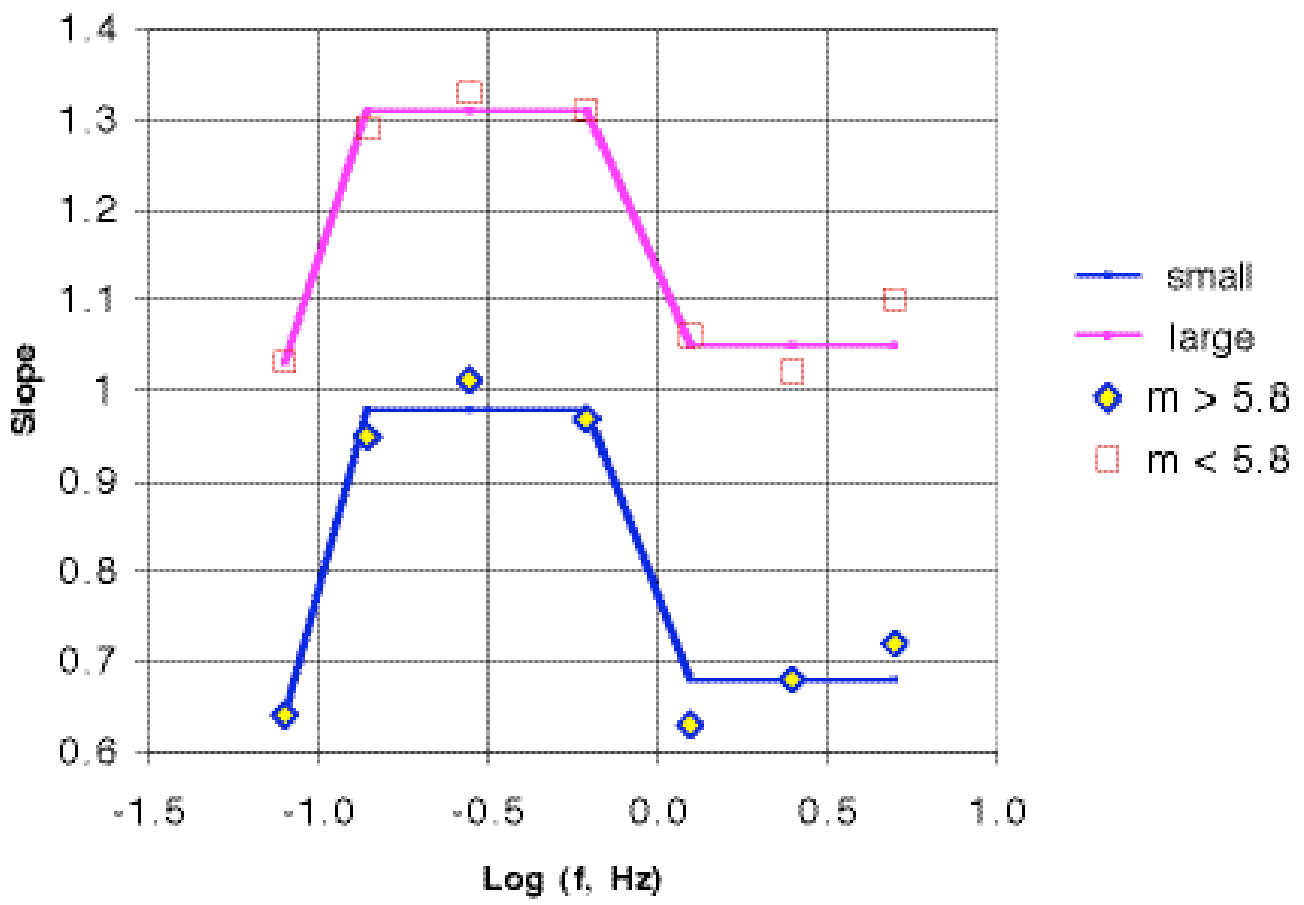

Figure 4. The coda-magnitude slope dependence on magnitude and frequency

STS UNTs, Scaling of coda spectra

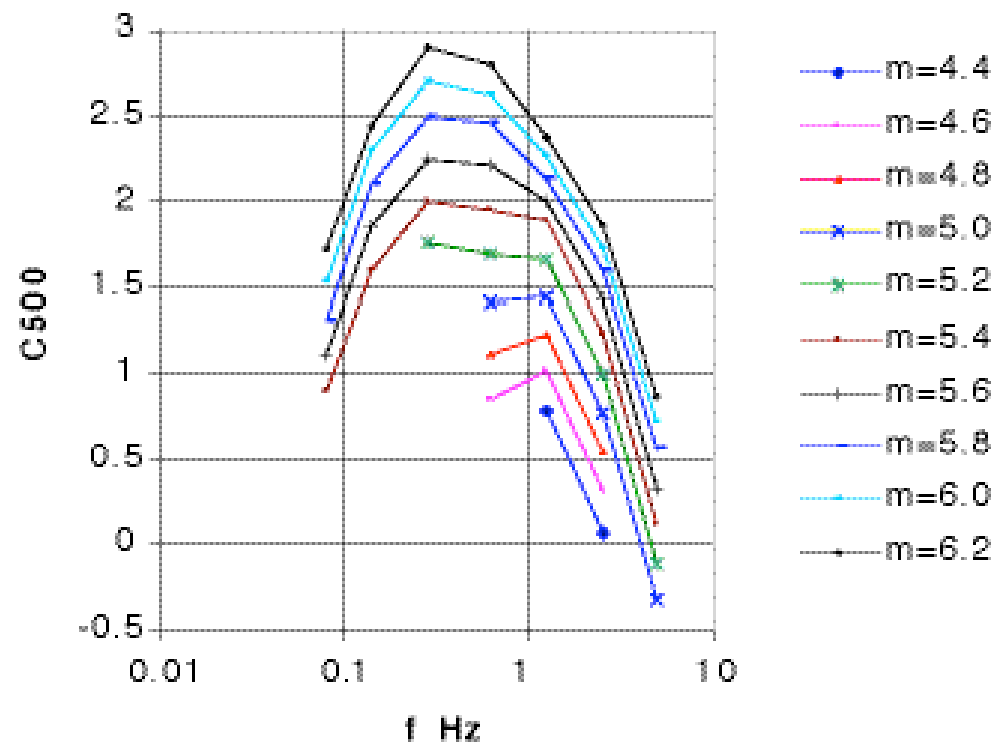

Figure 5. Average scaling of STS UNT coda spectra from Talgar ChISS records. 


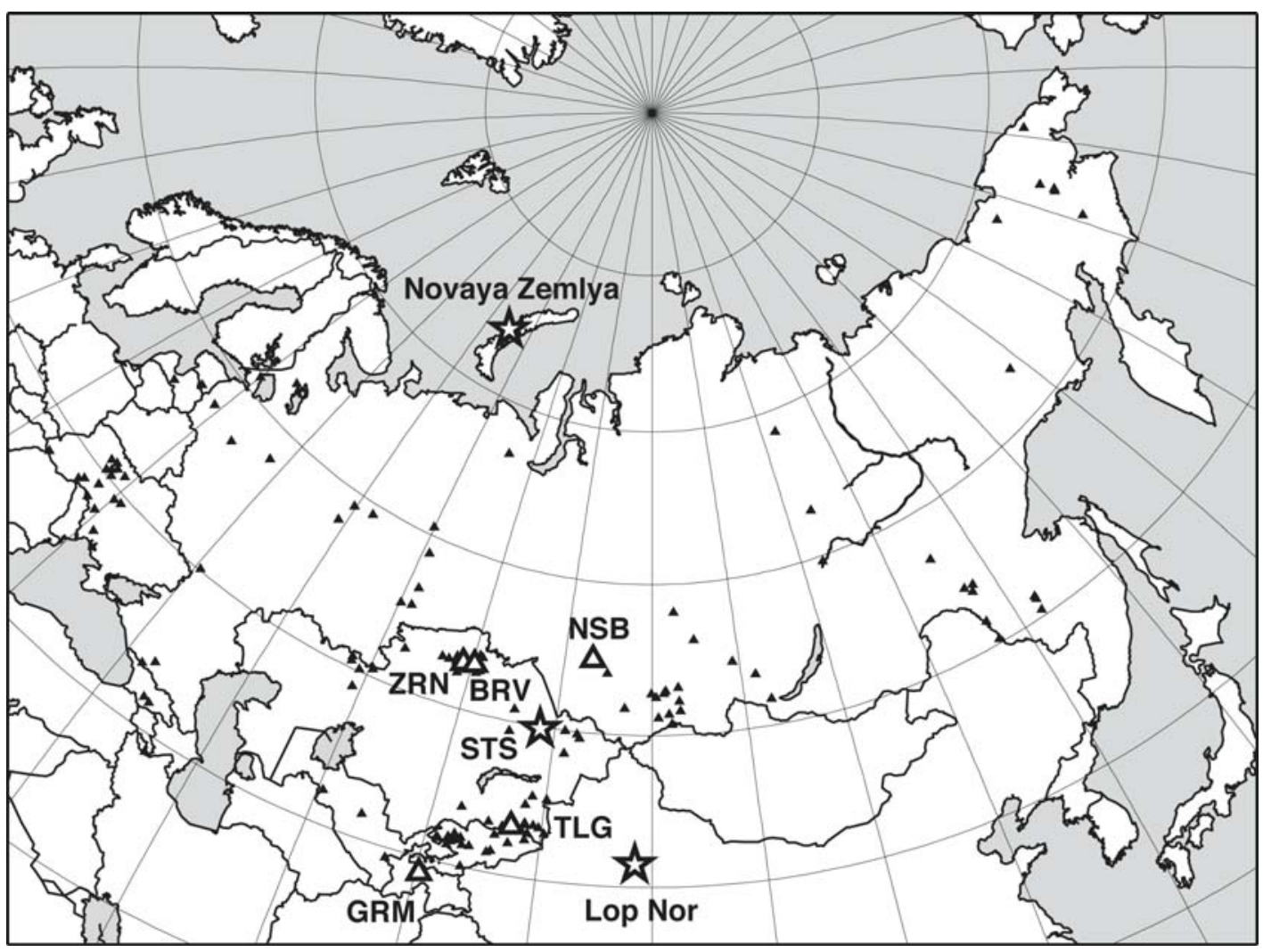

Figure 6. Map of Soviet stations and test sites in Asia. Four ChISS stations and the Borovoye station are represented by large triangles; other Complex Seismological Expedition by small triangles. Test sites are represented by stars. 


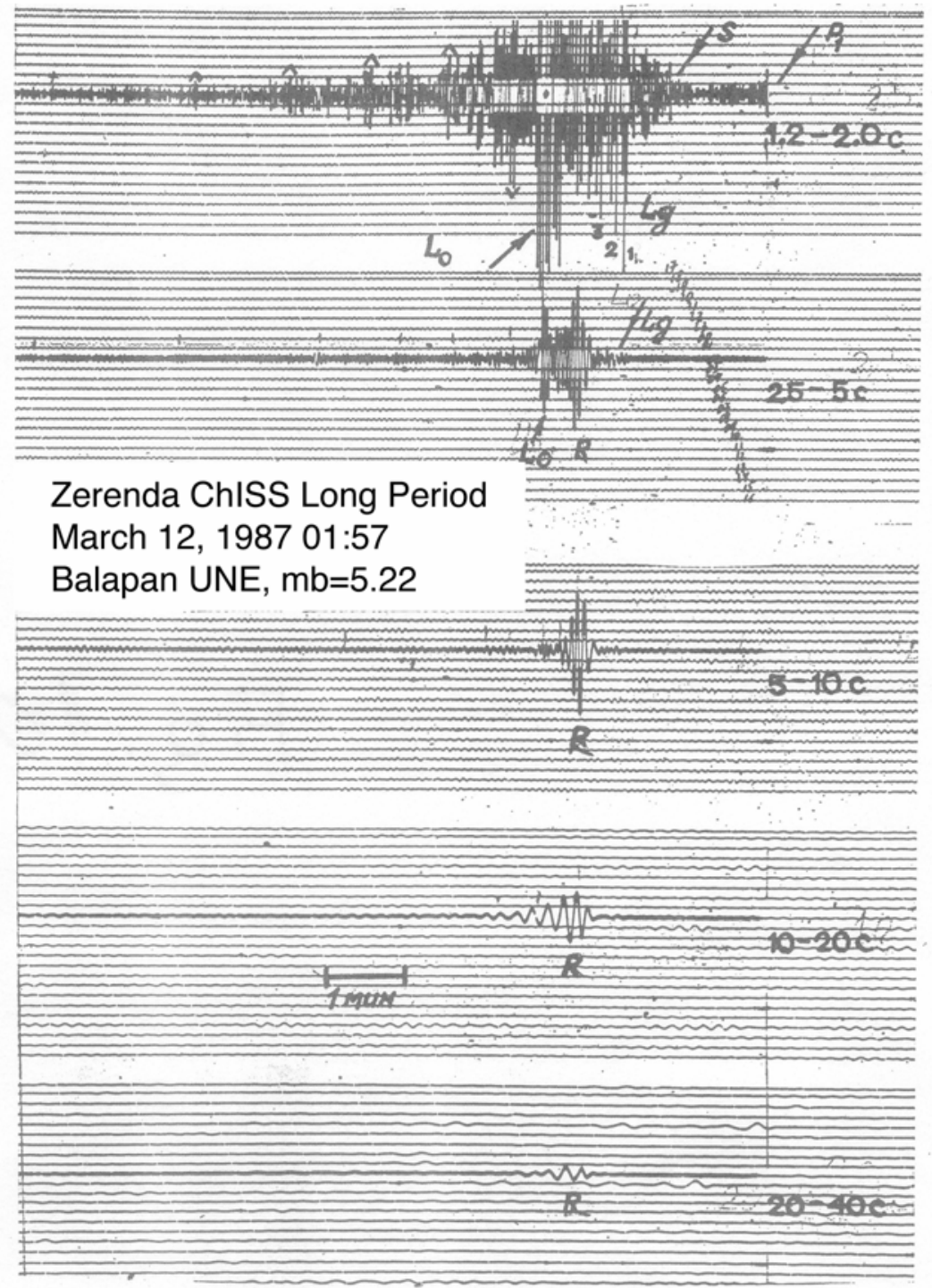

Figure 7. Long period ChISS seismograms from Zerenda. Time runs right to left. 

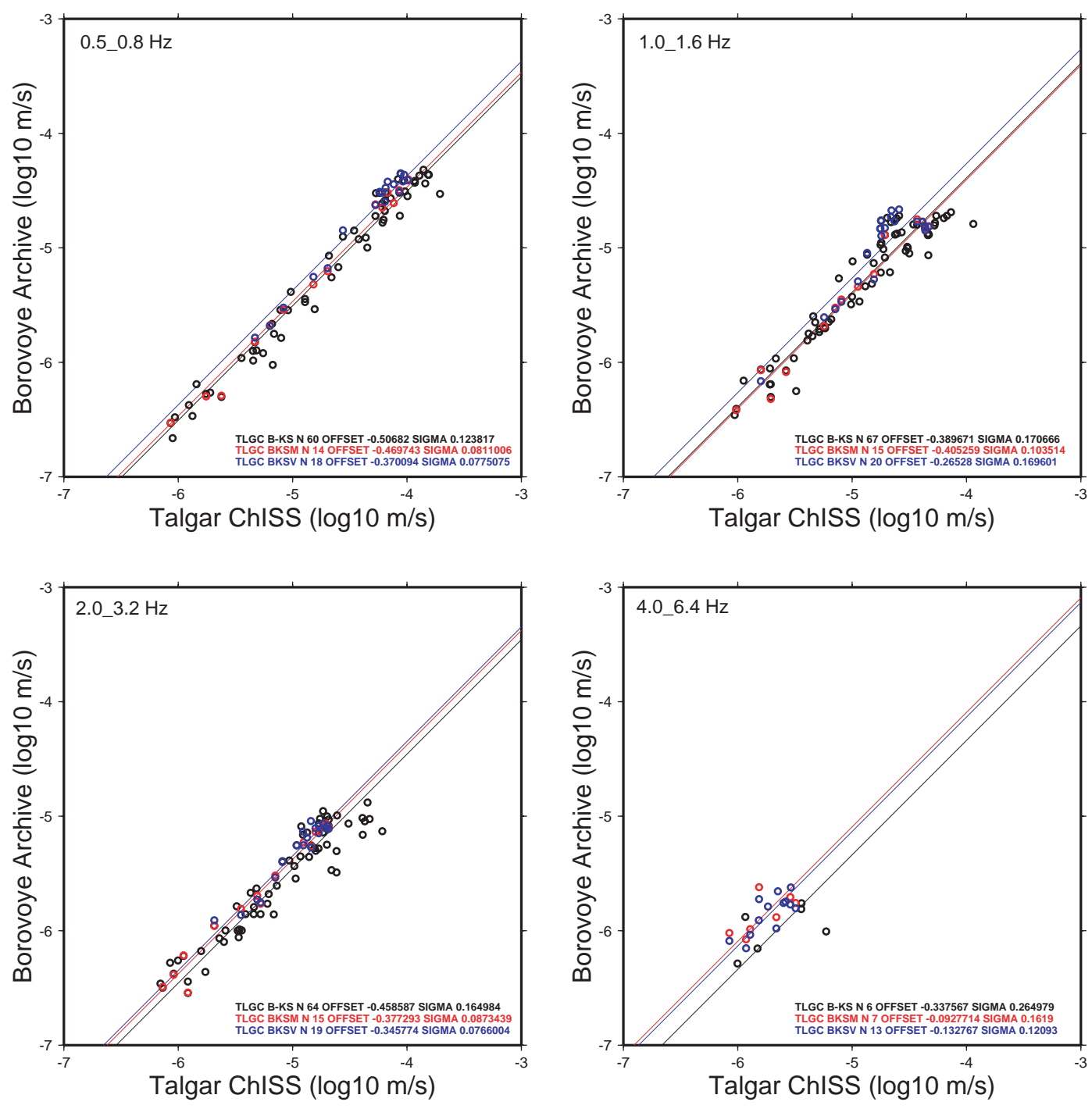

Figure 8. Comparison of path-corrected spectra between Talgar ChISS and Borovoye Archive stations.
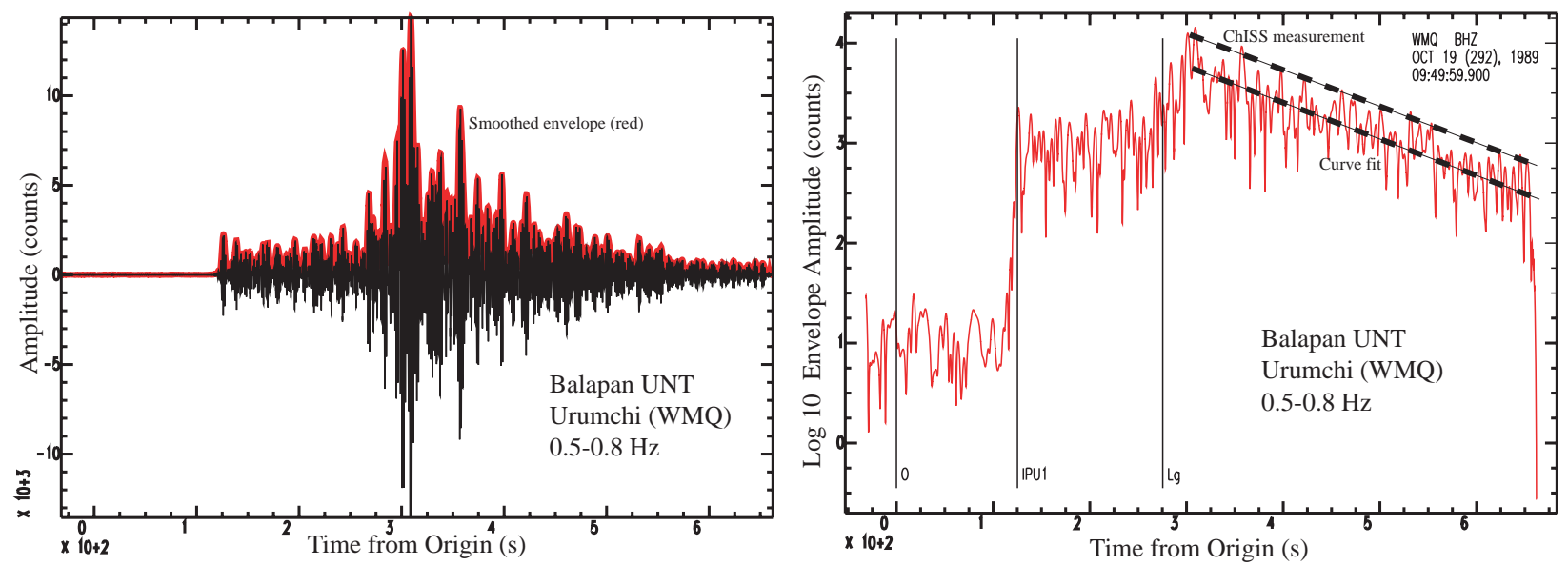

Figure 9. Example of offset resulting from ChISS measurement technique. This offset is absorbed in the site term when integrated into magnitude-yield processing for Asia. The calculation was performed in counts. 

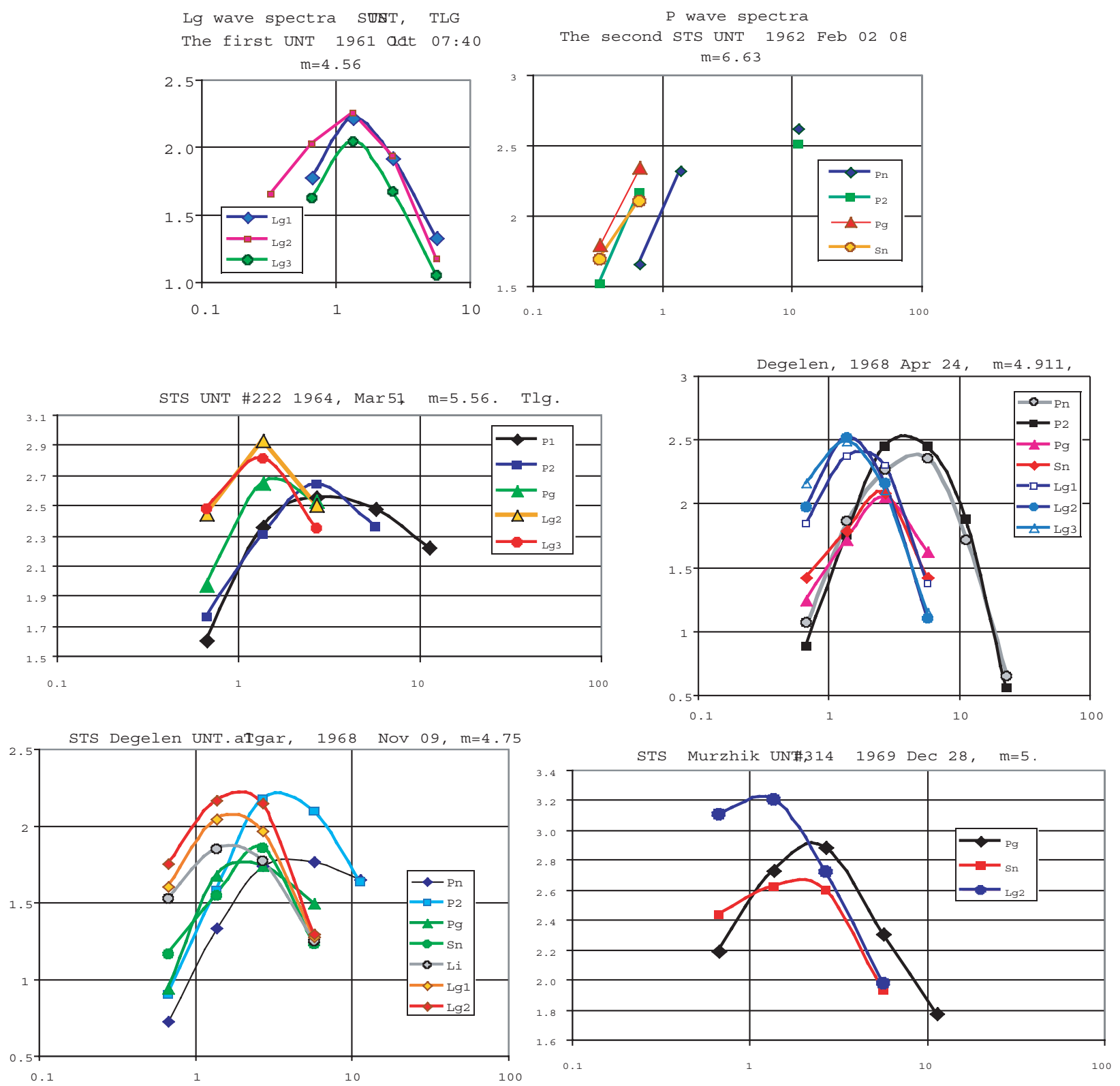

Figure 10. Examples of ChISS spectra $(\mathrm{nm} / \mathrm{s})$ for regional phases. Frequency in $\mathrm{Hz}$. 

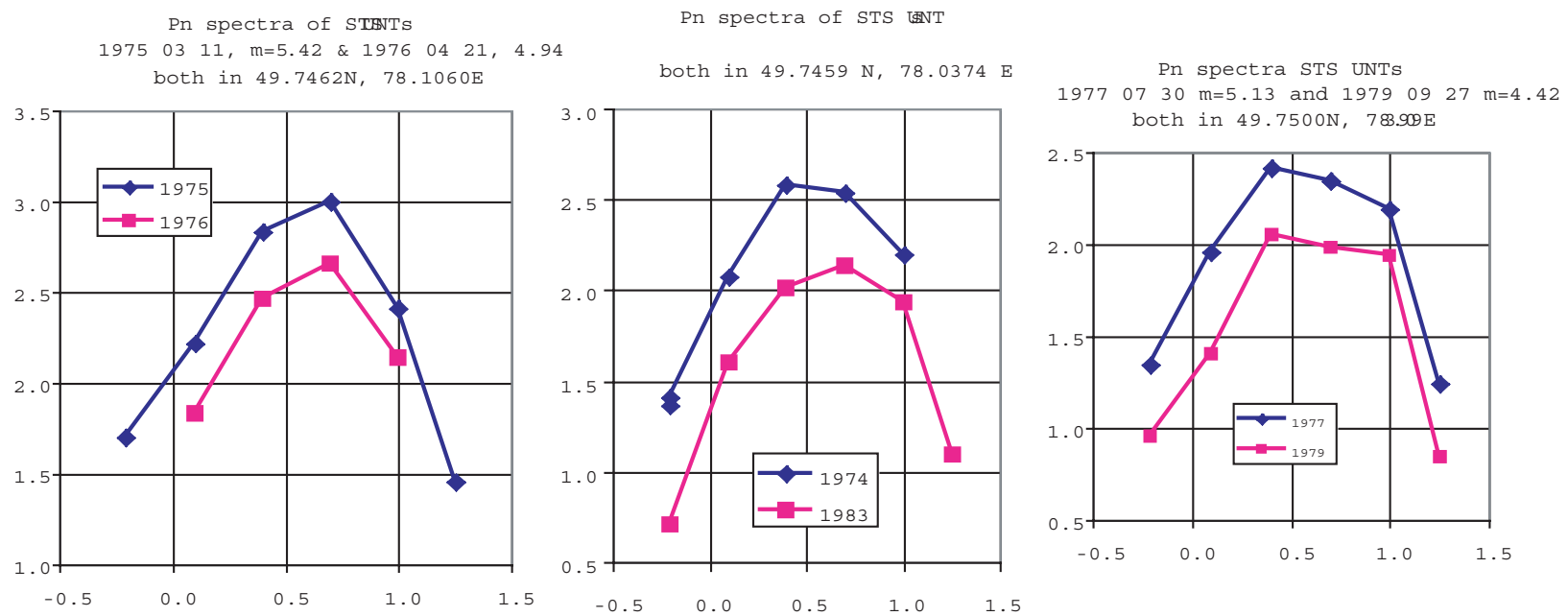

Figure 11. Examples of ChISS spectra $(\mathrm{nm} / \mathrm{s})$ for events in the same adit. Log10 frequency $(\mathrm{Hz})$ is shown.
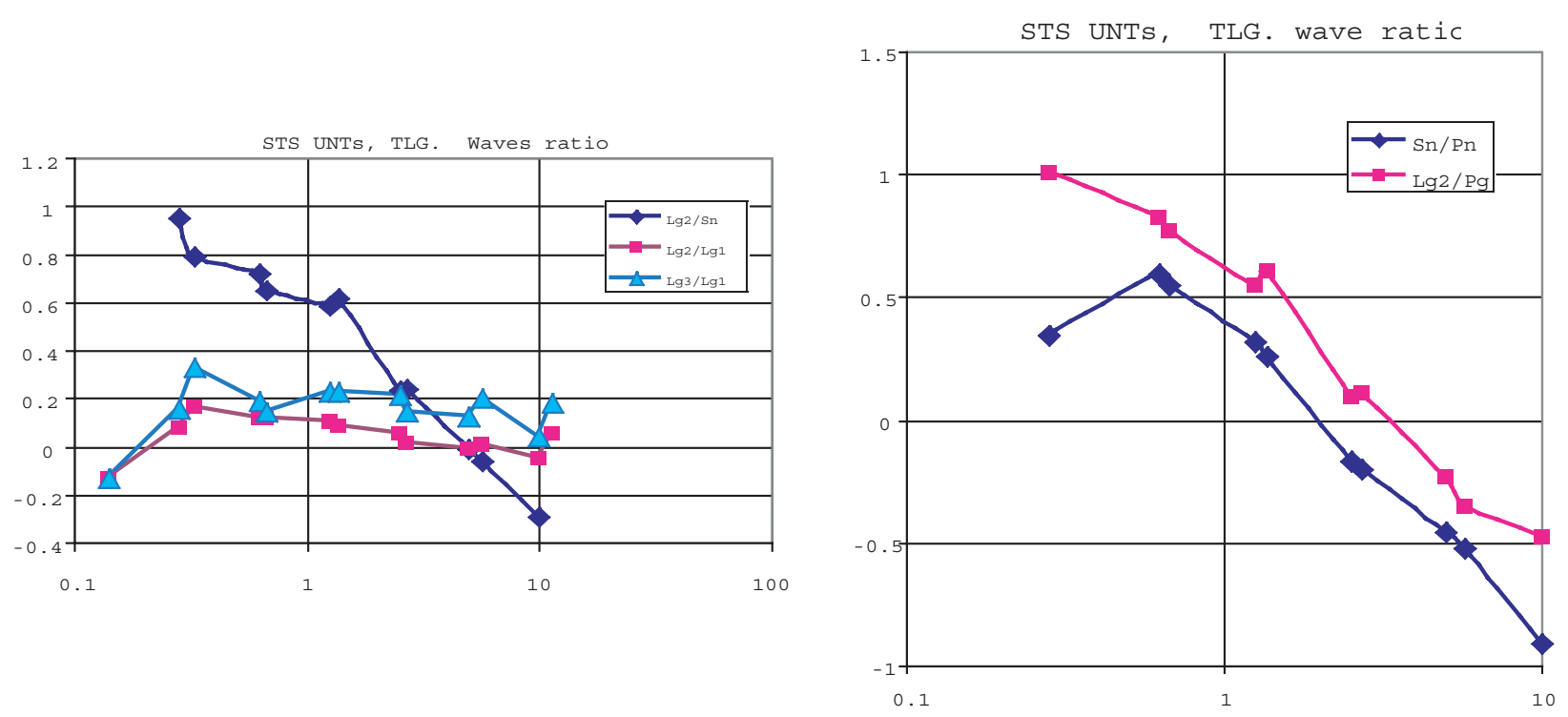

Figure 12. Spectral ratios versus frequency $(\mathrm{Hz})$ for Semipalatinsk events. 
STS UNTS, TLG LOg (P2/Pg), $\quad f=0.62 z$

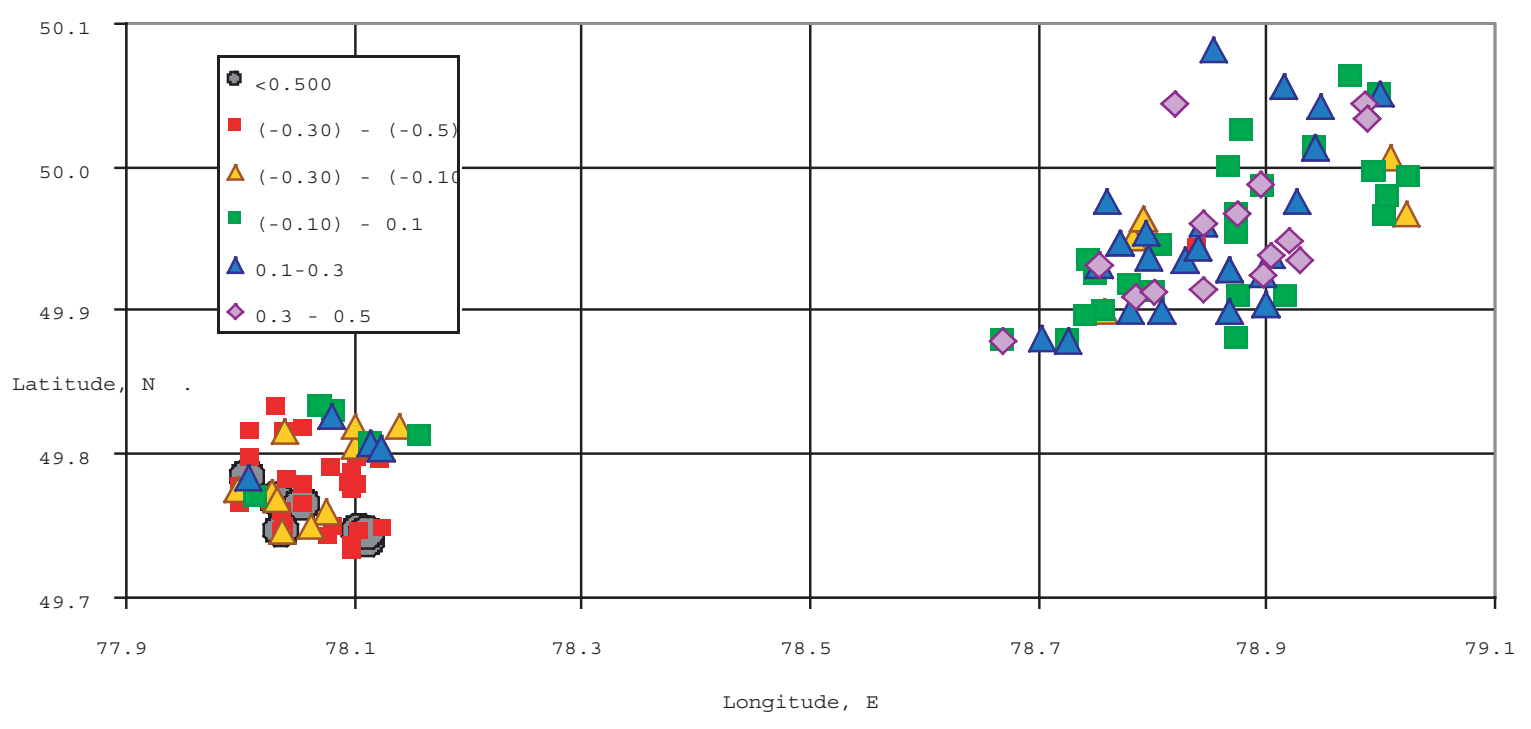

Figure 13. Geographical variation of the P2/Pg phase ratio for Balapan and Degelen events. 